\title{
RECONHECIMENTO DE SABERES: UM ESTUDO SOBRE O ESTADO DA ARTE
}

\author{
RECONOCIMIENTO DE SABERES: UN ESTUDIO SOBRE EL ESTADO DEL \\ $A R T E$
}

RECOGNITION OF KNOWLEDGE: A STUDY ON THE STATE OF THE ART

\author{
Elenita Eliete DE LIMA RAMOS ${ }^{1}$ \\ Miriam de Cassia do Carmo Mascarenhas MATTOS ${ }^{2}$
}

RESUMO: O texto é o resultado de estudos sobre "Reconhecimento de Saberes" iniciado pelas autoras no Instituto Federal de Santa Catarina (IFSC), em 2014. Tal pesquisa surgiu da constatação da necessidade de um maior aprofundamento teórico sobre o tema. O trabalho teve por objetivo traçar o delineamento do estado da arte do reconhecimento de saberes por meio de um mapeamento de artigos, teses e dissertações que abordam o tema. $\mathrm{O}$ universo de pesquisa ficou constituído de 8 artigos, 4 dissertações e uma tese, totalizando 13 documentos, produzidos de 2006 a 2016. Na análise dos documentos pode-se constatar que as políticas de certificação profissional e de reconhecimento de saberes ganharam destaque a partir das iniciativas para desenvolvimento e certificação de competências nos países europeus. Percebeu-se que as políticas implementadas de formação e certificação profissional são, em sua maioria, fortemente orientadas pela "teoria das competências" e pelas "necessidades do mercado de trabalho", em detrimento de uma concepção integral de educação. Concluiu-se que a implementação de dispositivos de reconhecimento de saberes não se dá sem tensões e comporta contradições que refletem as perspectivas dos grupos distintos que compõem a sociedade, desencadeando disputas que envolvem questões político-epistemológicas importantes. Se por um lado se fortalece a avaliação por competências, apoiada nos pressupostos da teoria do capital humano, fortemente voltado para uma concepção da educação para o mercado de trabalho, por outro, fortalecem-se, também, aqueles que tomam essas políticas como um mecanismo de justiça social, voltado para o atendimento das demandas históricas de movimentos sociais de direito à educação.

PALAVRAS-CHAVE: Reconhecimento de saberes. Validação de saberes. IFSCFlorianópolis. CERTIFIC. Certificação profissional.

RESUMEN: El texto es el resultado de la continuidad de estudios sobre "Reconocimiento de Saberes" iniciado por las autoras en el Instituto Federal de Santa Catarina (IFSC), en 2014. La investigación surgió de la constatación de la necesidad

\footnotetext{
${ }^{1}$ Instituto Federal de Santa Catarina (IFSC), Florianópolis - SC - Brasil. Professora e pesquisadora. Licenciada em Matemática e doutora em Educação Científica e Tecnológica pela UFSC. ORCID: <https://orcid.org/0000-0002-6764-5773>. E-mail: elenita.l.ramos@ gmail.com

${ }^{2}$ Universidade de Caxias do Sul (UCS), Caxias do Sul - RS - Brasil. Doutoranda em Educação pela UDESC. Professora e pesquisadora desde 2008. ORCID: 〈https://orcid.org/0000-0001-9597-987X>. Email: miriammattos@gmail.com
} 
de una mayor profundización teórica sobre el tema. El trabajo tuvo por objetivo demarcar el delineamiento del estado del arte del reconocimiento de saberes mediante un sondeo de artículos, tesis y disertaciones que abarcan la temática. El universo de la investigación está constituido por 8 artículos, 4 disertaciones y una tesis, totalizando 13 documentos, producidos de 2006 a 2016. Mediante el análisis de los documentos se puede constatar que las políticas de certificación profesional y de reconocimiento de saberes ganaron destaque a partir de las iniciativas para el desarrollo y la certificación de competencias en los países europeos. También se constata que las políticas implementadas de formación y certificación profesional son, en su gran mayoría, fuertemente orientadas por la "teoría de las competencias" y por las "necesidades del mercado de trabajo", en una concepción integral de educación. Al final de la investigación fue posible constatar que la implementación de dispositivos de reconocimiento de saberes no se da sin tensiones y que abarca las contradicciones que reflejan las perspectivas de los distintos grupos que componen la sociedad, desencadenando disputas que engloban cuestiones políticoepistemológicas importantes. Si por un lado se fortalece la evaluación por competencias, respaldada en fundamentos de la teoría del capital humano, fuertemente volcados hacia una concepción de la educación para el mercado de trabajo, por otro lado, se fortalecen, también, aquellos que toman esas políticas como un mecanismo de justicia social, orientadas hacia la atención de las demandas históricas de movimientos sociales de derecho a la educación.

PALABRAS CLAVE: Reconocimiento de saberes. Validación de saberes. IFSCFlorianópolis. CERTIFIC. Certificación profesional.

ABSTRACT: The text is the result of the continuation of studies on "Recognition of Knowledge" initiated by the authors at the Federal Institute of Santa Catarina (IFSC) in 2014. This research emerged from the need for theoretical background on the subject. The objective of this study was to outline the state of the art of recognition of knowledge through a mapping of articles, theses and dissertations that deal with the theme. The scope of the research consisted of eight articles, four dissertations and one thesis, totaling thirteen documents, produced from 2006 to 2016. In the analysis of the documents, it can be seen that the policies of professional certification and recognition of knowledge have gained prominence from the initiatives for the development and certification of skills in European countries. It can be seen that the implemented training and professional certification policies are for the most part strongly oriented towards "competence theory" and "labor market needs," to the detriment of a comprehensive conception of education. It was concluded that the implementation of recognition of knowledge devices does not happen without tensions and carries contradictions that reflect the perspectives of the different groups that make up society, triggering disputes involving important political-epistemological issues. If, on the one hand, the evaluation of competences is strengthened, based on the presuppositions of the theory of human capital, strongly focused on a conception of education for the labor market, then on the other hand, those that take these policies as a mechanism of social justice, focused on meeting the historical demands of social movements with a right to education, are strengthened as well.

KEYWORDS: Recognition of knowledge. Validation of knowledge. IFSC-Florianópolis. CERTIFIC. Professional certification. 


\section{Introdução}

O processo de avaliação e reconhecimento de saberes adquiridos na vida e no trabalho pode assumir papel central na certificação de trabalhadores jovens e adultos. Sob essa condição, reconhecer saberes significa pensar estratégias pedagógicas que permitam ao trabalhador construir, por meio das dinâmicas avaliativas, uma oportunidade de ressignificação e organização do conhecimento adquirido, estimulando a curiosidade referente aos fenômenos sociais, científicos e tecnológicos. (BRASIL, 2014, p. 15)

O presente artigo é resultado da pesquisa realizada no curso de especialização em Educação Profissional e Tecnológica do IFSC, campus Florianópolis. Esta se pautou pela continuidade e aprofundamento de estudos sobre a temática "Reconhecimento de Saberes", iniciados pelas autoras em um projeto piloto de pesquisa no âmbito do IFSC. Tal projeto foi executado entre os meses de abril e julho de 2014, e teve como objetivo reconhecer e certificar saberes escolares, em nível de Ensino Fundamental, de trabalhadores da área de Turismo, Hospitalidade e Lazer previamente selecionados, possibilitando o ingresso destes sujeitos num curso $^{3}$ de educação profissional que eleva a escolaridade (Ensino Médio) ao mesmo tempo que reconhece e certifica os saberes adquiridos no trabalho ao longo da vida. Na época, foram certificados doze trabalhadores participantes do processo, $100 \%$ dos inscritos. ${ }^{4}$

Durante o desenvolvimento do projeto a equipe responsável constatou a necessidade de um maior aprofundamento teórico, sendo necessário, para tanto, o levantamento do estado da arte do tema "reconhecimento de saberes", objeto desta pesquisa, pois a partir do arcabouço teórico a ser levantado, possibilitar-se-ia uma visão geral do que vem sendo produzido na área, bem como a ordenação histórica da sua evolução e preenchimento das lacunas ainda existentes.

No decorrer da pesquisa buscou-se responder os seguintes questionamentos: Qual a origem e caminhos percorridos na educação profissional para a certificação através do reconhecimento de saberes adquiridos ao longo da vida de trabalhadores? Quais os resultados dessas experiências? para responder esses questionamentos definiuse como objetivo geral delinear o estado da arte sobre reconhecimentos de saberes. E

\footnotetext{
${ }^{3} \mathrm{O}$ curso em questão está inserido no Programa Nacional de Integração da Educação Profissional com a Educação Básica na modalidade de Educação de Jovens e Adultos (PROEJA) e na Rede Nacional de Certificação Profissional (CERTIFIC).

${ }^{4}$ Deste projeto resultou o artigo "Processo de reconhecimento e certificação de saberes escolares de trabalhadores: orientações teórico-metodológicas", publicado em 2015 na revista Percursos, compondo o dossiê "Educação de Jovens e Adultos". Revista Percursos, v. 16, n. 31, 2015.
} 
como objetivos específicos, realizar o mapeamento de artigos, teses e dissertações que abordassem o tema reconhecimento de saberes como processo de certificação de trabalhadores, bem como apresentar uma visão geral, de forma cronológica, do que vem sendo produzido sobre a temática.

A fundamentação teórica foi no campo da teoria crítica, buscando estabelecer o diálogo entre a proposta de reconhecimento de saberes e os conceitos de trabalho e educação, educação omnilateral e educação politécnica. Utilizou-se como aporte teórico alguns textos de Marx; Saviane; Frigotto; Meszaros; Paulo Freire e Manacorda. Também apresentou-se as bases legais e princípios para o reconhecimento de saberes no Brasil, destacando-se a rede Certific.

Uma das questões a ser colocada refere-se à legitimidade dos processos de reconhecimento de saberes. É legítimo reconhecer os conhecimentos adquiridos pelos trabalhadores em seus processos de trabalho e na vida social? É justo que estes trabalhadores, por terem adquirido tais conhecimentos em locais não formais, sejam impossibilitados de terem seus conhecimentos reconhecidos e validados?

Ao longo da pesquisa foi possível constatar que a implementação de dispositivos de reconhecimento de saberes não se dá sem tensões e comporta contradições que refletem as perspectivas dos grupos distintos que compõem a sociedade, pois as políticas nacionais que instituem e regulamentam os instrumentos de validação de saberes construídos ao longo da vida põem em jogo interesses de diferentes atores sociais, desencadeando disputas ideológicas e envolvem questões políticoepistemológicas importantes. Dessa forma, se por um lado se fortalece a avaliação por competências, apoiadas nos pressupostos da teoria do capital humano ${ }^{5}$, de uma concepção de educação para o mercado de trabalho, por outro, defende-se essas políticas como um mecanismo de justiça social, voltado para o atendimento das demandas históricas de movimentos sociais por direito à educação. É nessa última perspectiva que centramos nossa proposição.

Neste sentido, tem-se claro que a educação, e mesmo os processos de "reconhecimento dos saberes", sob a lógica capitalista, servem aos interesses do capital,

5 De acordo com Frigotto (2010), a Teoria do Capital Humano se constitui em uma teoria do desenvolvimento e, simultaneamente, em uma teoria da educação. No primeiro aspecto, a educação é concebida como produtora de capacidade de trabalho e, consequentemente, potencializadora de renda. Assim, a educação é colocada como um fator de desenvolvimento econômico, constituindo-se enquanto capital social e individual. No que diz respeito ao capital humano, enquanto teoria da educação, a prática educativa é reduzida a uma questão técnica, de modo que se trata de encontrar a forma mais adequada de ajustar requisitos educacionais a pré-requisitos do mercado de trabalho. 
em uma concepção envolta da lógica de dominação, que compreende o processo de degradação social em que a educação para o trabalho está inserida. E compreende-se que é preciso buscar um contraponto, com concepções e práticas educativas de reconhecimentos de saberes que levem em conta uma formação dialógica, omnilateral e politécnica.

\section{Metodologia}

Em relação aos traços metodológicos desta pesquisa, em busca de um estudo em estado da arte, teve-se como base Romanowski e Ens (2006), sendo definidos os descritores, as fontes de pesquisa, realizados dois levantamentos bibliográficos, leitura e apresentação dos conteúdos.

A pesquisa foi realizada entre janeiro e julho de 2016. Foram utilizados como descritores os termos: Reconhecimento de saberes; Certificação de saberes; Certificação de trabalhadores, aprendizagem ao longo da vida; reconocimiento y validacion de conocimientos adquiridos. CERTIFIC.

As fontes de pesquisa foram o banco de teses e dissertações ${ }^{6}$ da Coordenação de Aperfeiçoamento de Pessoal, do Ministério da Educação - Capes, e o Banco de Dados de Teses e dissertações do IBICT $^{7}$. Também foram pesquisadas as base de dados da Scielo $^{8}$ - e a Rede de Revistas Científicas de América Latina y el Caribe, España y Portugal - A Redayc.

Compuseram este estudo 13 documentos, sendo 8 artigos, 1 tese e 4 dissertações, que seguem detalhados abaixo em dois quadros, separados por tipo e em ordem cronológica.

Quadro 1 - Artigos e relatórios utilizados na pesquisa

1. FERNÁNDEZ, F. S. Reconocimiento y validación de los aprendizajes adquiridos en la experiencia: la ley francesa de modernización social. 2006. Disponível em: <http://www2.uned.es/andresbello/documentos/florentino.pdf>. Acesso em: 21 jul. 2016.

6 Portal de Teses da CAPES <http://capesdw.capes.gov.br>, é o sistema online oficial do Governo Brasileiro para depósito de teses e dissertações brasileiras, vinculado ao Ministério da Educação (MEC).

${ }^{7}$ Banco de Teses do IBICT <http://bdtd.ibict.br/pt>, é um mecanismo de busca que integra todos as Bibliotecas Digitais de Teses e Dissertações (BDTD) das Universidades Brasileiras que utilizam o sistema BDTD do IBICT. (UFSCAR, 2016).

${ }^{8}$ Biblioteca eletrônica que abrange uma coleção selecionada de periódicos científicos brasileiros. 
2. FERNÁNDEZ, Ó. M.; FERNÁNDEZ, F. S. Los sistemas de reconocimiento y acreditación de los aprendizajes no formales e informales: referências históricas, funciones socioeducativas y perspectiva teórica. Revista de Educación, n. 348, p. 253-281, Enero-abril, 2009. Disponível em: <http://www.revistaeducacion.mec.es/re348/re348_11.pdf> Acesso em: 25 jul. 2016.

3. MANFREDI, S. M. Uma política de Certificação profissional orientada para a inclusão social. Linhas Críticas, Brasília, DF, v. 16, n. 30, p. 27-48, jan./jun. 2010. Disponível em: <http://periodicos.unb.br/index.php/linhascriticas/article/viewFile/1427/1063>. Acesso em: 21 jul. 2016.

4. FISCHER, M. C. B.; GODINHO, C. F.; CAVALLI, Â. Beatriz. Aproximações entre as políticas de Certificação profissional no Brasil e em Portugal. R. Educ. Públ. Cuiabá, v. 20, n. 42, p. 7189 jan./abr., 2011.

5. BARROS, R. A Agência Nacional de Educação e Formação de Adultos (ANEFA): Um marco na europeização da agenda pública do setor. Revista Portuguesa de Educação, v. 26, n. 1, 2013, pp. 59-86. Universidade do Minho, Braga, Portugal. Disponível em: <http://www.lume.ufrgs.br/handle/10183/83303?locale=pt_BR>. Acesso em: 21 jul. 2016.

6. ANÍBAL. A. A singularidade do Sistema Nacional de Reconhecimento, Validação e Certificação de Competências: génese, caraterização, situação atual e pistas para o futuro. Centro de investigação e estudo de sociologia. [Relatório CIES e-Working Paper N. 149 Portugal], 2013. Disponível em: <http://hdl.handle.net/10071/5005> Acesso em: 21 jul. 2016.

7. ALCOFORADO. L. M. Reconhecimento, validação e Certificação de saberes experienciais: desafios para a formação continuada e as relações de trabalho. Trabalho \& Educação; Belo Horizonte, v.23, n.3, p. 13-30, set-dez, 2014. Disponível em: <http://www.portal.fae.ufmg.br/seer/index.php/trabedu/article/viewFile/2197/1518>. Acesso em: 21 jul. 2016.

8. HICKENBICK, C.; RAMOS, E. E. de L.; MATTOS, M. C.C.M. Processo de reconhecimento e Certificação de saberes escolares de trabalhadores: orientações teórico-metodológicas. Revista Percursos, v.16, n. 31, 2015.

Fonte: Levantamento bibliográfico realizado pela pesquisadora em 2016.

Nesta etapa foram recuperados 8 artigos. Da mesma forma que ocorreu com as teses e dissertações, observou-se que a maioria dos documentos recuperados perpassam a certificação e competências no âmbito profissional. Com exceção do último artigo, que apresenta o tema reconhecimento no âmbito dos "saberes escolares", cuja experiência relatada desencadeou essa proposta de pesquisa. Destaca-se que os artigos são datados da última década, e um dos artigos aborda especificamente "referenciais teóricos".

Quadro 2 - Teses e dissertações utilizadas na pesquisa 
1. SILVA, M. J. L. F. da. Dimensões formativas dos processos de reconhecimento, validação e Certificação de competências desenvolvidos num centro novas oportunidades. Dissertação (Mestrado em Formação de Adultos e Desenvolvimento Local). Instituto Politécnico de Portalegre; Escola Superior de Educação de Portalegre. 2011. Disponível em: <http://comum.rcaap.pt/handle/10400.26/8462> Acesso em 20 nov. 2016.

2. RODRIGUES, C. B. Reconhecimento, avaliação e Certificação de aprendizagens e competências: experiências na educação profissional. Dissertação (mestrado em educação) Universidade Católica de Brasília, 2013. Disponível em: < http://professor.cee.ce.gov.br/index.php/espacodaaula/modalidades-de-ensino/file/2430reconhecimento-avaliacao-e-CERTIFICacao-de-aprendizagens-e-competencias-experiencias-naeducacao-profissional?start=160>. Acesso em: 21 jul. 2016.

3. CAVALCANTE, E. A. Reconhecimento de saberes e Certificação profissional em tecnologia do pescado: um estudo de caso do Programa CERTIFIC no nordeste. Dissertação (PósGraduação em Políticas Públicas e Gestão da Educação Superior) Universidade Federal do Ceará, 2014. Disponível em: <http://www.repositorio.ufc.br/handle/riufc/8577>. Acesso em: 21 jul. 2016.

4. COSTA, R. C. D. Rede CERTIFIC: percursos e percalços na formulação da política de reconhecimento e Certificação de saberes dos trabalhadores. Tese (Doutorado em educação) Universidade Federal do Rio Grande do Sul, 2015. Disponível em: <http://www.lume.ufrgs.br/handle/10183/131023> Acesso em: 20 dez. 2016.

5. LIMA, N. V. Reconhecimento de saberes do trabalho e Certificação profissional: experiência da Inglaterra. Dissertação (mestrado em Conhecimento e Inclusão Social em Educação) Universidade Federal de Minas Gerais, 2015. Disponível em: <http://www.bibliotecadigital.ufmg.br/dspace/handle/1843/BUBD>. Acesso em: 21 jul. 2016

Fonte: Levantamento bibliográfico realizado pela pesquisadora em 2016-2

Observa-se que foram recuperadas apenas uma tese e quatro dissertações, sendo que todas abordam o tema CERTIFIC, ou seja, certificação e reconhecimento de saberes profissionais.

Destaca-se, na lista de trabalhos apresentados, uma dissertação que aborda a reconhecimento de saberes na Inglaterra, contribuindo para uma visão mais abrangente do tema, com a realidade de outro país. Outro fato importante é que todas as teses e dissertações recuperadas são muito recentes, sendo a mais antiga do ano de 2011. Com relação aos artigos, o mais antigo é datado de 2006, apontando para a inovação da temática pesquisada.

\section{Considerações finais}

Sobre a base daquele reino da necessidade, lá onde cessa o trabalho voltado para uma finalidade externa, e para além da esfera da produção material propriamente dita, surge, de fato, para Marx, o verdadeiro reino da liberdade, vale dizer, o desenvolvimento das 
capacidades humanas como fim em si mesmo. (MANACORDA, 1964, p. 15).

Ao longo desta pesquisa foi possível perceber, a partir dos contextos apresentados nos treze documentos analisados, que as políticas de certificação profissional e de reconhecimento de saberes ganharam destaque a partir da reorganização do processo produtivo, com a modernização dos meios de produção e a flexibilização dos postos de trabalho. Em grande medida, a partir das iniciativas para desenvolvimento e certificação de competências nos países europeus, são impulsionadas ações governamentais após documentos e orientações emanados da Organização Internacional do Trabalho - OIT - e da União Europeia sobre a necessidade de implementação de programas de reconhecimento da aprendizagem ao longo da vida.

Dentre as publicações que abordam o tema, destacaram-se: o Livro Branco "Ensinar e aprender: rumo à sociedade cognitiva" e o relatório "Os quatro pilares da Educação", conhecido como "Relatório Delors". Outro fato que merece destaque foi a definição, pelo Conselho dos Ministros e pelo Parlamento Europeu, do ano de 1996 como Ano Europeu da Educação e da Formação ao Longo da Vida. Tal ação fortaleceu a difusão da noção de aprendizagem ao longo da vida, se tornando lema das políticas educativas europeias.

Embora em muitos casos as experiências ainda sejam de pequeno vulto e o tema prossiga despertando polêmicas, percebe-se que as políticas implementadas de formação e certificação profissional são fortemente orientadas pela "teoria das competências" e pelas "necessidades do mercado de trabalho", em detrimento de uma concepção integral de educação.

Concepções como essa prosseguem sendo fortalecidas com iniciativas como a da União Europeia, que estipulou o ano de 2018 como data-limite para que seus paísesmembros implementem sistemas que permitam a identificação, a documentação, a avaliação e a certificação de todas as formas de aprendizagem, conforme afirmou Lima (2015).

De toda forma, destaca-se como positivo o fortalecimento internacional da necessidade de valorizar e reconhecer a aprendizagem ao longo da vida, em processos informais e não formais, construída fora do ambiente escolar, também como válida. E é positivo, também, observar que a implementação de dispositivos de reconhecimento de saberes não se dá sem tensões e comporta contradições que refletem as perspectivas dos 
grupos distintos que compõem a sociedade, desencadeando disputas que envolvem questões político-epistemológicas importantes.

Após a leitura e fichamento de todos os documentos, pode-se perceber que quatro dos treze trabalhos fazem estudos comparativos. Fernandes e Fernandes (2006), comparam as políticas de certificação entre França e Espanha (país de origem dos autores). E dão continuidade a seus estudos em (2009), também fazendo um comparativo entre EUA, Canadá e o contexto Europeu. Na mesma linha Ficher; Godinho e Cavalli (2011), comparam as experiências de Brasil e Portugal. Costa (2015), apesar de seu foco ser o contexto brasileiro da Rede Certific, também apresenta um capítulo analisando a experiência Francesa de forma comparativa.

Já a dissertação de mestrado de Lima (2015) apresenta de forma detalhada a experiência de certificação no contexto da Inglaterra. Não identificamos pesquisas que trouxessem um maior detalhamento de experiências relativamente ao tema em estudo, no contexto francês e espanhol, a exemplo do que ocorreu em relação à Inglaterra e Portugal.

Destaque-se que a experiência portuguesa foi a mais citada no contexto internacional: elas estão detalhadas nos trabalhos de Barros (2013); Anibal (2013) e Silva (2011). E também no já citado estudo de Ficher; Godinho e Cavalli (2011), que relaciona as duas experiências de forma comparativa, entre Brasil e Portugal.

Consideramos que a experiência portuguesa foi a que mais inspirou as concepções da rede CERTIFIC no Brasil, inclusive quanto à metodologia de certificação, mesmo percebendo que o programa português pareça possibilitar maior profundidade no processo, inclusive com mais recursos de atendimento aos trabalhadores.

Importante registar que no início desse projeto nossa perspectiva era de construção de um caminho teórico, a partir dos contextos observados no levantamento do estudo do estado da arte que sustentasse um projeto de reconhecimento de saberes escolares. Mas no decorrer da pesquisa notou-se que as diversas experiências apresentadas, tanto em nível internacional como a brasileira, eram por demais heterogêneas tanto em suas fundamentações teórico-metodológicas, quanto em seus aspectos históricos, culturais, sociais e educativos específicos de cada país.

Assim, o que se concluiu com essa pesquisa não foi a indicação da construção de um único caminho teórico, mas de muitas possibilidades. Dentre as citações teóricas 
que nos instigaram a buscar um maior aprofundamento, cita-se a aprendizagem experiencial, de Kolb (1984) e a zona de desenvolvimento proximal de Vygotsky.

Neste contexto, destacamos o texto de Alcoforado (2014), professor em Coimbra, que defende o direito do reconhecimento social de aprendizagens desenvolvidas em ambientes não formais e informais, mas ressalta a dificuldade de colocar em prática a ideia de reconhecimento de competências e saberes. Por isso busca uma revisão teórica com base sociocultural, apresentando um modelo de reconhecimento, validação e certificação de competências a fim de ajudar na reconfiguração das dimensões mais coletivas das relações de trabalho. Alcoforado (2014) se utiliza de Habermas, Vygotski e Pineo, para sustentar uma teoria de que os saberes mais significativos para a nossa atividade profissional advêm da própria ação e não da teoria. $\mathrm{O}$ autor busca em Freire uma dimensão ideológica emancipatória para retirar os obstáculos à sua real humanização no trabalho e na vida.

Em relação ao contexto de certificação no Brasil, destacam-se os trabalhos de Manfredi (2010), Cavalcante (2014), Costa (2015) e Hickenbick; Ramos e Mattos (2015). Estes apresentam desde experiências concretas de certificação, até estudos analíticos dos processos de elaboração das políticas públicas. Diante dos índices de certificação apresentados por Costa (2015), com relação ao estado brasileiro do Rio Grande do Sul, onde "dos 719 trabalhadores gaúchos inscritos na Rede CERTIFIC em 2010, apenas 1 foi certificado em 2012", nos colocamos a refletir sobre a necessidade não só de pesquisas que estudem com mais aprofundamento os poucos processos de certificação que vem ocorrendo no Brasil e os reais números das certificações no país, como também a construção de novas metodologias que levem em conta a perspectiva dos trabalhadores.

A partir da leitura de Costa, buscamos obter dados de certificação nas fontes oficiais do governo e pouco foi encontrado ${ }^{9}$, o que nos remete à fragilidade da política de certificação brasileira e à necessidade de mais informações, principalmente em relação aos seus resultados, que podem ser uma boa fonte de pesquisa para futuros estudos.

${ }^{9}$ No artigo "Reconhecimento de saberes profissionais na Educação de Jovens e Adultos: o projeto formativo do IFSC para a EJA", publicado na Coletânea de Textos Confintea Brasil + 6, as autoras Claudia Hickenbick e Elenita Eliete de Lima Ramos apresentam alguns dados da SETEC, que também fortalecem nossas considerações. Em relação aos atendidos pelo CERTIFIC, afirmam que "Dos 3.567 que acessaram o programa, somente 134 receberam certificação e 1.161 foram encaminhados para cursos de qualificação ou de elevação de escolaridade". Assim elas concluem que "Considerando-se que a meta era capacitar e favorecer a inclusão de 10 mil trabalhadores brasileiros no mercado, os números atingidos pelo CERTIFIC, inicialmente, podem ser considerados baixos". (HICKENBICK; RAMOS, 2016, p. 204). 
Entre as experiências brasileiras, o projeto piloto ${ }^{10}$ que motivou esta pesquisa se diferenciou de todos os outros, proporcionando a certificação do reconhecimento de saberes escolares de trabalhadores em nível de Ensino Fundamental, e seus resultados foram positivos, pois a maioria dos trabalhadores certificados deram prosseguimento aos seus estudos. Também se diferenciou por utilizar como arcabouço teórico e metodológico os princípios e diretrizes para a educação popular nas políticas públicas.

Algumas das leituras realizadas apontaram que as certificações obtidas pelos trabalhadores não têm significado melhora nos seus salários ou nos níveis de empregabilidade. Ou ainda que os processos têm beneficiado com a certificação efetiva um número de pessoas muito inferior ao pretendido.

Diante disso, parece-nos plausível a sustentação de Anibal (2013), quando afirma que o que há de importante na educação de adultos dificilmente se espelha em termos de taxas de emprego e de aumentos remuneratórios, mas pode medir-se em termos de ganhos de justiça social. No caso português, com expressiva parcela da população pouco escolarizada devido à ausência de investimentos em educação, os ganhos podem ser assim descritos: acesso a mecanismos de reconhecimento de competências adquiridas fora do sistema formal de ensino; equidade e integração na sociedade da informação; ampliação na capacidade de aprendizagem e na pró-atividade na definição de projetos de vida; aumento de auto-estima e da motivação dos adultos para a educação ao longo da vida; melhoras em atividades relacionadas à leitura, escrita e comunicação oral; flexibilidade e integração do sistema no desenvolvimento articulado de competências escolares e profissionais, entre outros.

Dos 13 trabalhos analisados nesta pesquisa, todos se remetem a uma concepção do reconhecimento de saberes como mecanismo de justiça social, alguns com mais veemência que outros. Ao mesmo tempo, estes, em suas revisões teóricas, análises e conclusões das práticas de reconhecimento de saberes em suas especificidades, contextualizam que as políticas públicas implementadas pelos governos citados são fortemente voltadas para uma concepção da educação para o mercado de trabalho, a partir das orientações de organismos internacionais.

Fernández e Fernández (2009), por exemplo, identificam a controvérsia entre os "favoráveis" e os "contrários" às experiências de reconhecimento e validação de saberes. São favoráveis a tais experiências, observam sua forte motivação pelas

${ }^{10}$ Tal projeto está descrito no artigo Hickenbick; Ramos e Mattos (2015). 
orientações de órgãos multilaterias emanadas das necessidades do mercado de trabalho e reconhecem seu potencial como mecanismo de justiça social, mas não expressam um posicionamento claro sobre a segunda polêmica.

Já, Fischer, Godinho e Cavalli (2011), apresentam um posicionamento crítico à "Teoria do Capital Humano" e à ênfase internacional à qualificação do trabalhador numa perspectiva que transfere "do Estado e das agências de formação para o indivíduo a responsabilidade pela sua formação e qualificação profissional".

Numa perspectiva mais contundente, a portuguesa Rosane Barros (2013) não titubeou em manifestar-se sobre essa polêmica ao condenar não o reconhecimento e validação de saberes em Portugal, mas sim a orientação hegemônica nas políticas emanadas da ANEFA, matizadas por concepções neoliberais. A autora combate o que ocorre em nível europeu, onde "ao invés de uma visão mais humanista, predominou um entendimento paliativo para a missão que as atividades públicas de educação e formação dirigidas a adultos deveriam desempenhar".

Por outra via de raciocínio, Alexandra Aníbal (2013) não poupa críticas ao processo mais recente de desmonte da experiência de reconhecimento e validação de saberes em Portugal, ao afirmar que o importante na educação de adultos em Portugal não podia ser mensurado em taxas de emprego e de aumentos remuneratórios, mas sim em efeitos sociais como ganhos de justiça social.

Assim, concluímos que, se por um lado se fortalece a avaliação por competências, apoiada nos pressupostos da teoria do capital humano, fortemente voltado para uma concepção da educação para o mercado de trabalho, por outro, fortalecem-se, também, aqueles que tomam essas políticas como um mecanismo de justiça social, voltado para o atendimento das demandas históricas de movimentos sociais de direito à educação, concepção que defendemos ao longo desse trabalho.

Por fim espera-se que este trabalho contribua para o aprimoramento dos processos de certificação de saberes escolares e profissionais, sendo mais um elemento impulsionador da oferta e continuidade de projetos de reconhecimento de saberes, com um viés que realmente seja favorável aos trabalhadores em uma formação mais ampla e completa.

\section{REFERÊNCIAS}


ALCOFORADO, L. M. Reconhecimento, validação e Certificação de saberes experienciais: desafios para a formação continuada e as relações de trabalho. Trabalho \& Educação, Belo Horizonte, v. 23, n. 3, p. 13-30, set./dez., 2014.

ANÍBAL, A. A singularidade do Sistema Nacional de Reconhecimento, Validação e Certificação de Competências: génese, caraterização, situação atual e pistas para o futuro. Centro de investigação e estudo de sociologia. Relatório CIES e-Working Paper, n. 149 - Portugal, 2013. Disponível em: <http://hdl.handle.net/10071/5005>. Acesso em: 21 jul. 2016.

BARROS, R. A Agência Nacional de Educação e Formação de Adultos (ANEFA): Um marco na europeização da agenda pública do setor. Revista Portuguesa de Educação, v. 26, n. 1, p. 59-86, 2013.

CAVALCANTE, E. A. Reconhecimento de saberes e Certificação profissional em tecnologia do pescado: um estudo de caso do Programa CERTIFIC no nordeste. Dissertação (Mestrado em Políticas Públicas e Gestão da Educação Superior). Universidade Federal do Ceará, 2014.

COSTA, R. C. D. Rede CERTIFIC: percursos e percalços na formulação da política de reconhecimento e Certificação de saberes dos trabalhadores. Tese (Doutorado em educação) Universidade Federal do Rio Grande do Sul, 2015.

CUNHA, D. M.; LIMA, N. V. Reconhecimento e Certificação de saberes construídos no ambiente de trabalho: uma análise comparada dos dispositivos inglês e brasileiro. Disponível em: <http://www.sbec.org.br/evt2012/trab11.pdf>. Acesso em: 24 set. 2014.

FERNÁNDEZ, F. S. Reconocimiento y validación de los aprendizajes adquiridos en la experiencia: la ley francesa de modernización social. Disponível em:

<http://www2.uned.es/andresbello/documentos/florentino.pdf>. Acesso em: 21 jul. 2016.

FERNÁNDEZ, Ó. M.; FERNÁNDEZ, F. S. Los sistemas de reconocimiento y acreditación de los aprendizajes no formales e informales: referencias históricas, funciones socioeducativas y perspectiva teórica. Revista de Educación, n. 348, enero/abril, p. 253-281, 2009.

FERREIRA, N. S. A. As pesquisas denominadas "estado da arte". Educação \& Sociedade, n. 79, ago., 2002.

FISCHER, M. C. B.; GODINHO, C. F.; CAVALLI, Â. Beatriz. Aproximações entre as políticas de Certificação profissional no Brasil e em Portugal. R. Educ. Públ. Cuiabá, v. 20, n. 42, p. 71-89 jan./abr., 2011.

FISCHER, M. C. B.; FRANZOI, N. L. Formação Humana e Educação profissional. Diálogos possíveis. Educação, Sociedade e Culturas, n. 29, p. 35-51, 2009.

FRIGOTTO, G. A produtividade da escola improdutiva. 9 ed. São Paulo: Editora Cortez, 2010. 
HICKENBICK, C.; RAMOS, E. E. de L.; MATTOS, M. C.C.M. Processo de reconhecimento e Certificação de saberes escolares de trabalhadores: orientações teórico-metodológicas. Revista Percursos, v. 16, n. 31, 2015.

LIMA, N. V. Reconhecimento de saberes do trabalho e Certificação profissional: experiência da Inglaterra. Dissertação (Mestrado em Conhecimento e Inclusão Social em Educação) Universidade Federal de Minas Gerais, 2015.

MANACORDA. Marx e a pedagogia moderna. São Paulo: Cortez, 2007.

MANFREDI, S. M. Uma política de Certificação profissional orientada para a inclusão social. Linhas Críticas, Brasília, v. 16, n. 30, p. 27-48, jan./jun., 2010.

MANFREDI, S. M. Educação Profissional no Brasil, São Paulo: Cortez: autores associados, 2002.

MARX, K. Processo de trabalho e processo de produção de mais valia. In: MARX, K. O Capital. 7 ed. Difitel, 1983, Disponível em: <www.marxistas.org/portugues/ marx/1867/ocapital-v1vol07.htm\#topp>. Acesso em: 02 jan. 2016.

MORAES, C. S. V.; LOPES NETO, S. Educação, formação profissional e Certificação de conhecimentos: considerações sobre uma política pública de Certificação profissional. Educ. Soc., Campinas, v. 26, n. 93, p. 1435-1469, set./dez., 2005.

RAMOS, E. E. de L.; HICKENBICK, C. Projeto formativo para a EJA: a integração entre processo educativo e prática social na educação profissional. Anais... CONGRESSO NACIONAL DE PROGRAMAS EDUCATIVOS PARA JOVENS, ADULTOS E IDOSOS. 1., 2015, Campos dos Goytacazes. Campos dos Goytacazes, 2015.

RAMOS, E. E. de L. Propondo práticas e desafiando certezas: um estudo em turma do Proeja numa perspectiva de Educação Matemática Crítica. Tese (Doutorado em Educação Científica e Tecnológica). Universidade Federal de Santa Catarina, Florianópolis, 2011.

RODRIGUES, C. B. Reconhecimento, avaliação e Certificação de aprendizagens e competências: experiências na educação profissional. Dissertação (Mestrado em educação). Universidade Católica de Brasília, 2013.

ROMANOWSKI, J. P.; ENS, R. T. As pesquisas denominadas do tipo "estado da arte" em educação. Diálogo Educ., Curitiba, v. 6, n.19, p.37-50, set./dez., 2006.

ROMANOWSKI, J. P. As licenciaturas no Brasil: um balanço das teses e dissertações dos anos 90. Tese (Doutorado em Educação) - Faculdade de Educação da Universidade de São Paulo, São Paulo, 2002.

SILVA, M. J. L. F. da. Dimensões formativas dos processos de reconhecimento, validação e Certificação de competências desenvolvidos num centro novas oportunidades. Dissertação (Mestrado em Formação de Adultos e Desenvolvimento 
Local). Instituto Politécnico de Portalegre; Escola Superior de Educação de Portalegre. 2011.

STEFFEN, E. M. Sistema de Certificação de competências no Brasil e em Portugal.

Trabalho \& Educação, v. 18, n.1, jan./abr., 2009.

\section{Como citar este artigo:}

DE LIMA RAMOS, Elenita Eliete.; MATTOS, Miriam de Cassia do Carmo Mascarenhas. Reconhecimento de saberes: um estudo sobre o estado da arte. Revista Ibero-Americana de Estudos em Educação, Araraquara, v. 13, n. 4, p. 1711-1725, $\begin{array}{llll}\text { out./dez., } & 2018 . & \text { E-ISSN: } & \text { 1982-5587. }\end{array}$ 10.21723/riaee.unesp.v13.n4.out/dez.2018.10853

Submissão em: 28/12/2017

Revisões requeridas: $20 / 03 / 2018$

Aprovação final em: 20/04/2018 